\title{
ESCHERICHIA COLI, PRODUTORAS DE SHIGATOXINAS DETECTADAS EM FEZES DE BOVINOS LEITEIROS
}

\section{H.I.G. Vicente, L.A. do Amaral, A.P. Nunes, C.S. Lorenzon}

Universidade Estadual Paulista, Faculdade de Ciências Agrárias e Veterinárias, Departamento de Medicina Veterinária Preventiva e Reprodução Animal, Via de Acesso Prof. Paulo Donato Castellane, s/nº, CEP14884900, Jaboticabal, SP, Brasil. E-mail: isahinig@yahoo.com.br

\section{RESUMO}

Este trabalho teve como objetivo determinar a prevalência de Escherichia coli produtoras de Shigatoxinas (STEC) e E. coli dos sorogrupos O157, O111 e O113 em rebanhos leiteiros do Município de Jaboticabal, SP, Brasil. A presença de sequências gênicas $s t x_{1}$, st $x_{2}$ e eae foi detectada pela reação em cadeia da polimerase (PCR) em amostras de fezes. Todas as amostras stx e eae positivas foram submetidas a uma nova reação de PCR para detecção das sequências $r f b$ O157, O111 e O113. Observou-se uma alta prevalência $(72,16 \%)$ de sequências stx nas fezes dos bovinos, sendo que o perfil genotípico encontrado com maior frequência foi o stx $x_{1}$ associado à st $x_{2}$. Os coeficientes de prevalência das sequências $r f b$ O157, O111 e O113 foram, respectivamente, 14,77\%, 0,2\% e $30,83 \%$. Animais de todos os rebanhos (100\%) apresentaram em suas fezes STEC e E. coli O113 e os sorogrupos O157 e O111 foram observados em 60,0\% e 10,0\% dos rebanhos, respectivamente. Concluiu-se que a alta prevalência de STEC detectada em rebanho leiteiro evidenciada nas fezes de bovinos desempenham um papel importante na contaminação ambiental e podem oferecer risco de agravo à saúde pública.

PALAVRAS-CHAVE: Shigatoxigênica, prevalência, E. coli O157, E. coli O111, E. coli O113.

\section{ABSTRACT}

SHIGATOXIN-PRODUCING ESCHERICHIA COLI DETECTED IN DAIRY CATTLE FECES. The purpose of this study was to determine the prevalence of Shigatoxigenic Escherichia coli (STEC) and serogroups O157, O111 and O113 in dairy cattle from Jaboticabal, state of São Paulo, Brazil. Feces samples were collected from 10 herds and assessed for the presence of the virulence genes st $x_{1}$, st $x_{2}$ and eae by polymerase chain reaction (PCR). All samples positive for stx and eae were submitted to a second PCR reaction targeting the sequences $r f b$ O157, $r f b$ O111 and $r f b$ O113. A high prevalence of $s t x(72.16 \%)$ was detected in the fecal samples, the most frequent being st $x_{1}$ associated to $s t x_{2}$. The prevalence of sequences $r f b$ O157, $r f b \mathrm{O} 111$ and $r f b \mathrm{O} 113$ was $14.77 \%, 0.2 \%$ and $30.83 \%$, respectively. STEC and serogroup O113 was identified in all herds (100\%), and serogroups $\mathrm{O} 157$ and $\mathrm{O} 111$ were observed in $60 \%$ and $10 \%$ of the herds. In conclusion, the high STEC prevalence detected in dairy herds evidences that bovine feces might play an important role as a contamination source in the region of Jaboticabal.

KEY WORDS: Shigatoxigenic, prevalence, E. coli O157, E. coli O111, E. coli O113.

\section{INTRODUÇÃO}

Escherichia coli fazem parte da microbiota normal do intestino de mamíferos. A maioria delas são comensais inofensivos, entretanto, existem cepas patogênicas e que provocam diarréia (DoyLE et al., 1995). Sabe-se que algumas E. coli produzem citotoxinas muito potentes, chamadas Shigatoxina 1 e Shigatoxina 2, e são capazes de aderir à mucosa intestinal (BARRETT et al., 1992).

Dentre as cepas de E. coli que produzem Shigatoxinas, classificadas como E. coli shigatoxigênicas
(STEC), existem as que são altamente patogênicas aos seres humanos. Estas podem pertencer a uma extensa gama de sorogrupos $\mathrm{O}$, entretanto, particularmente as Escherichia coli enterohemorrágicas O157, O111, e mais recentemente O113, parecem ser as responsáveis pela maioria dos casos mais graves (Paton; Paton, 1999). Estes micro-organismos são uma ameaça à saúde pública uma vez que as patologias por eles provocadas são, geralmente, de natureza grave como, por exemplo, a colite hemorrágica, a síndrome hemolítica urêmica e a púrpura trombocitopênica trombótica, que podem 
ser fatais, principalmente para crianças e idosos (Vold et al., 1998).

A transmissão de STEC está frequentemente associada ao consumo de alimentos contaminados, particularmente carne moída e hambúrguer, crus ou mal cozidos (GrifFin; TAUXE, 1991). A transmissão de pessoa a pessoa, assim como de animal a pessoa, também é possível (Doyle et al., 1995; PATON; PATON, 1998).

O reservatório principal das STEC são os bovinos (BLANCO et al., 1993; HANCOCK et al., 1994). STEC podem entrar na cadeia de alimentação humana de várias maneiras, mais frequentemente, por meio da contaminação direta ou indireta da carne, após o abate, com fezes ou conteúdo intestinal contendo o patógeno (PATON; Paton, 1998).

Tendo em vista as informações retro apresentadas, esta pesquisa foi realizada com a finalidade de verificar a prevalência de STEC em rebanhos leiteiros e também de fornecer dados que poderão ser utilizados para melhor direcionar as medidas de controle desses importantes patógenos.

\section{MATERIAL E MÉTODOS}

\section{Amostragem}

Foi extraída uma amostra aleatória simples de dez rebanhos, produtores de leite situados no $\mathrm{Mu}$ nicípio de Jaboticabal, Estado de São Paulo, Brasil. Amostras de fezes de 467 animais foram colhidas no período de estiagem, entre julho e agosto de 2003. A prevalência dos sorogrupos O157, O111 e O113 foi analisada por PCR nas amostras STEC positivas, ou seja, naquelas onde foram detectadas sequências gênicas stx $x_{1}$ stx 2 por meio de PCR multiplex.

Os resultados das amostras de fezes foram analisados considerando-se três faixas etárias: bezerros $(<4$ meses), novilhas (de 5 meses a 2 anos) evacas ( $>2$ anos).

\section{Colheita de amostras}

As amostras de fezes foram colhidas com suabe retal de todos os bovinos, com ou sem diarréia, de cada propriedade, com exceção de uma, em que foram colhidas amostras dos animais colocados a disposição pelo proprietário. Omeio de cultura CaryBlair (Copan, Itália) foi utilizado para o transporte das amostras (CERQueIra et al., 1999), que foram levadas ao laboratório em caixas de material isotérmico, contendo gelo reciclável, sendo processadas imediatamente após a chegada.

\section{Reação em cadeia da polimerase (PCR)}

Preparo das amostras
Todas as amostras colhidas foram semeadas em superfície de placas contendo ágar cistina lactose eletrólito deficiente (CLED - Difco, France) e levadas à incubação a $37^{\circ} \mathrm{C}$ por 18 -24h., para obtenção de crescimento confluente. Após esse período, o crescimento polimicrobiano foi coletado em aproximadamente $2 \mathrm{~mL}$ de tampão fosfato salino (PBS-D; pH $7,4)$ formando uma suspensão polimicrobiana. Cem microlitros desta suspensão foram então diluídos 10 vezes em água bidestilada ultrapura. O DNA alvo foi obtido pelo aquecimento da suspensão bacteriana diluída, por $10 \mathrm{~min}$. em banho à temperatura de $100^{\circ}$ C, como descrito por SAMBROOK et al. (1989). Concomitantemente, $0,5 \mathrm{~mL}$ da suspensão bacteriana concentrada foi misturada a $0,5 \mathrm{~mL}$ de TSB duplo, com $20 \%$ de glicerol, em duplicata, e estocado a $-20^{\circ}$ C (Cerqueira et al., 1999).

PCR multiplex para detecção de $s t x_{1}$ stx ${ }_{2}$ eae em E. coli STEC

Utilizou-se a metodologia descrita por CHINA et al. (1996), com os primers citados a seguir: Ep1 - 5' AGG CTT CGT CAC AGT TG 3' Ep2 - 5' CCA TCG TCA CCA GAG GA 3' Stx1R - 5' AGA GCG ATG TTA CGG TTTG 3' Stx1F - 5' TTG CCC CCA GAG TGG ATG 3' Stx2R - 5' TGG GTT TTT CTT CGG TATC $3^{\prime}$ Stx2F - 5' GAC ATT CTG GTT GAC TCT CTT 3'

Foram incluídos controles em todas as reações. Um controle negativo sem DNA foi usado, assim como controles de reação incluindo DNA extraídos de E. coliStx-negativo DH5 (K12), STECStx-positivo cepa E40705 - stx e eae (CPHL, London) e STEC Stx-positivo cepa E30138 - stx ${ }_{2}$ e eae. Os amplicons e respectivos pesos moleculares são: Eae - 570bp, Stx ${ }_{1}-388$ pb e Stx $x_{2}-807 p b$.

PCR Multiplex para detecção de $r f b$ O157, O113, O111 em E. coli STEC

Todas as amostras stx e eae positivas foram submetidas a uma segunda reação de PCR, de acordo com os procedimentos descritos por PATON; PATON (1999), usando os primers descritos a seguir:

O157 F - 5' CGG ACA TCC ATG TGA TAT GG 3'

O157 R - 5' TTG CCT ATG TAC AGC TAA TCC $3^{\prime}$ O113 F - 5' AGC GTT TCT GAC ATA TGG AGTG 3' O113 R - 5' GTG TTA GTA TCA AAA GAG GCT CC 3'

O111F-5' TAGAGAAATTATCAAGTT AGTTCC ${ }^{\prime}$ O111 R - 5' ATA GTT ATG AAC ATC TTG TTT AGC 3'

Foram incluídos controles em todas as reações: controlenegativo sem DNA, E. coliStx-negativo DH5 (K12), STEC Stx-positivo cepa E40705 ou E30138 (O157), E. coli O113:H21 (O113) e EPEC cepa B171 (O111). Os amplicons erespectivos pesos moleculares são: O157 - 259bp, O113 - 593pb e O111- 406pb. 


\section{RESULTADOS E DISCUSSÃO}

Uma alta prevalência $(72,16 \%)$ de sequências stx (Fig. 1) foi detectada nas fezes de bovinos pertencentes a rebanhos leiteiros do Município de Jaboticabal, SP, por meio da PCR. Uma vez que, uma reação positiva com primers específicos para $s t x_{1} \mathrm{e}$ $s t x_{2}$ é suficiente para confirmar a presença de STEC na amostra (PATON; PATON, 2005), pode-se concluir que $72,16 \%$ das amostras de fezes analisadas apresentaram STEC.

Esta prevalência deSTEC quando comparada aos dados de propriedades leiteiras de diferentes países encontrados na literatura, os quais apresentam uma grande variação, desde 8,0\%, nos EUA (WelLs et al., 1991) até44,3\%, naSuíça (BusAToetal.,1999), mostra-se relativamente superior. Este resultado é concordante como descrito por outros pesquisadores do Brasil que também registraram prevalências superiores, como 82\% no Rio de Janeiro (CERQueIra et al., 1999) e 49\% no Rio Grande do Sul (Moreira et al., 2003).

Ainda não está claro que proporção de STEC detectadas nas fezes de bovinos ou em carcaças é capaz decausar doença em seres humanos. Contudo, GYLES et al. (1998) defende a idéia de que todas as STEC podem ser patogênicas em condições adequadas. Isto significa que cepas menos virulentas podem causar o mesmo tipo de doença que cepas mais virulentas, desde que haja uma dose suficientemente alta e imunidade suficientemente baixa do indivíduo infectado. Certamente existem STEC não patogênicas, entretanto cada cepa deSTEC deveria ser considerada uma potencial E. coli enterohemorrágica.

O coeficiente de prevalência do sorogrupo O157, de $14,77 \%$, encontrado nas fezes dos animais (Fig. 1), é bem mais elevado que os resultados apresentados por HANCOCK et al. (1997) e Vold et al. (1998), os quais obtiveram prevalências de $1,0 \%$. CHAPMAN et al. (1993) isolaram E. coli O157 de 4\% das amostras de fezes de bovinos antes do abate. Destes animais O157 positivos nas fezes, 30\% também apresentaram o sorogrupo O157 na carcaça após o abate, além disso, 8\% dos bovinos $\mathrm{O} 157$ negativos nas fezes apresentaram contaminação por $\mathrm{O} 157$ na carcaça. Isto indica que os bovinos são um reservatório de $E$. coli $\mathrm{O} 157$ e que a contaminação da carcaça durante o abate ou processamento pode ser o meio pelo qual a carne e seus subprodutos se contaminem. Carnes, provenientes não só do gado de corte, como também do gado leiteiro, têm sido associadas a surtos causados por E. coli O157:H7 (GRIFFIN; TAUXE, 1991).

STEC pertencentes ao sorogrupo O111 também têm sido encontradas em fezes de bovinos (BETTELHEIM, 2003). Somente $0,2 \%$ dos animais foram positivos para o $r f b$ O111 (Fig. 1). Wells et al. (1991), KOBAYASHI et al. (2001) e ORDEN et al. (2002) relataram as seguintes prevalências, respectivamente, $0,32 \%$,
0,56\% e 1,21\%. Embora o coeficiente de prevalência verificado tenha sido, relativamente, baixo, VICENTE et al. (2005) encontraram uma prevalência de 3,3\%, dois anos antes, em trabalho realizado nas mesmas propriedades, durante o período chuvoso.

Ademais se deve lembrar que a E. coli O111 é um dos sorogrupos de STEC mais importante, causa reconhecida de colite hemorrágica $(\mathrm{CH})$ e síndrome hemolítica urêmica (SHU) (BANATVALA et al., 2001). A maioria dos surtos em seres humanos causados por outras STEC, exluindo-se a E. coli O157, são atribuídos a cepas pertencentes a esse sorogrupo (BETTELHeim, 2003).

O coeficiente de prevalência de sequências $r f b$ de E. coli $\mathrm{O} 113$ encontrado nos bovinos neste trabalho foi de 30,83\% (Fig. 1). STEC O113 prevalentes no rebanho bovino apresentam grandes chances de entrar na cadeia de alimentação humana (PATON; PATON, 1999). O sorogrupo deSTEC O113 foi um dos primeiros a ser associado à SHU; segundo KARMALI et al. (1985), duas a cada 12 cepas de STEC isoladas de pacientes com SHU são de E. coli O113.

E. coli $\mathrm{O} 113$ já foi isolada de alimentos como, carne moída, carne bovina, linguiça e leite (WHO..., 1998), incluindo hambúrguer congelado comercializado no Município do Rio de Janeiro (CERQUeIRA et al., 1997). ARTHUR et al. (2002) encontraram 3,59\% das amostras de carcaça bovina contaminadas por E. coli O113, mesmo antes da evisceração, corroborando o demonstrado por BARKOCY-GALLAGHER et al. (2001), que o couro e as fezes de animais destinados ao abate são as principais fontes de contaminação por patógenos durante o processamento da carne.

Em acordo com a maioria dos trabalhos publicados até o momento, a maior prevalência de STEC foi observada entre novilhas $(86,09 \%)$, entretanto, a segunda maior prevalência foi encontrada em animais adultos $(68,89 \%)$ e a menor em bezerros (58,88\%), com diferença significativa ao nível de $5 \%$, contrariando resultados anteriores que descrevem a prevalência em novilhas e bezerros maior que em vacas. Resultados semelhantes aos deste trabalho foram obtidos por MoreIRA et al. (2003), no Brasil e por KoвAYASH et al. (2001) no Japão, estes também relataram maior prevalência entre novilhas e vacas.

Observou-se um coeficiente de prevalência de sequências $r f b \mathrm{O} 157$ e O111 significativamente maior, entre bezerros e novilhas, ao nível de $5 \%$. Os coeficientes de prevalência de sequência $r f b \mathrm{O} 113$ não apresentaram diferença significativa entre as categorias animais, ao nível de 5\%. Estes resultados são concordantes aos descritos por Wells et al. (1991) e RAHN et al. (1997). As razões para essas diferenças de prevalência entre faixas etárias, ainda são desconhecidas, mas podem refletir disparidade no desenvolvimento ruminal, dieta, resistência a infecções e outros fatores (WelLs et al., 1991). 
Coeficiente de Prevalência

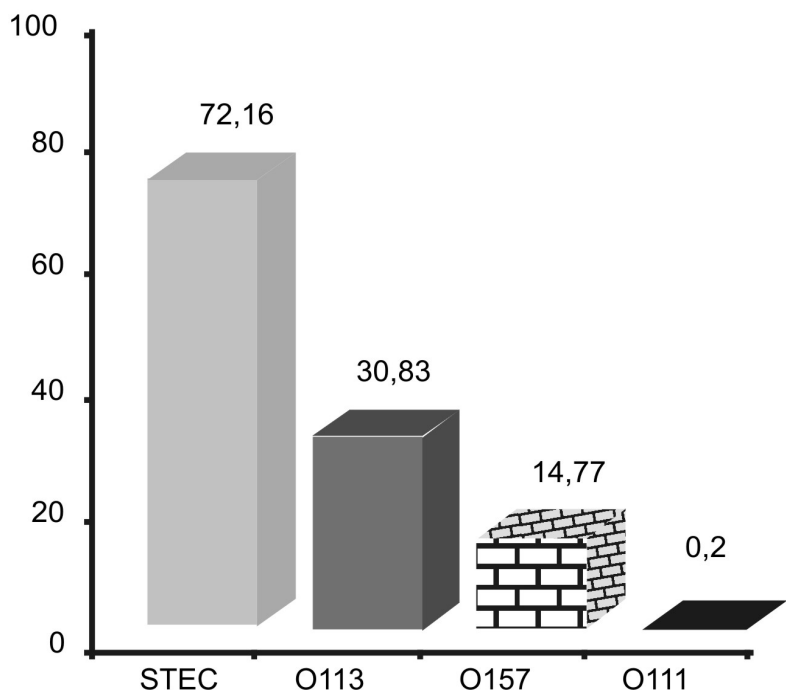

Fig. 1 - Coeficientes de prevalência de sequências stx e rfb O113, O111 e O157 de Escherichia coli em amostras de fezes de bovinos, detectadas por Reação em Cadeia de Polimerase. Jaboticabal, SP, 2003

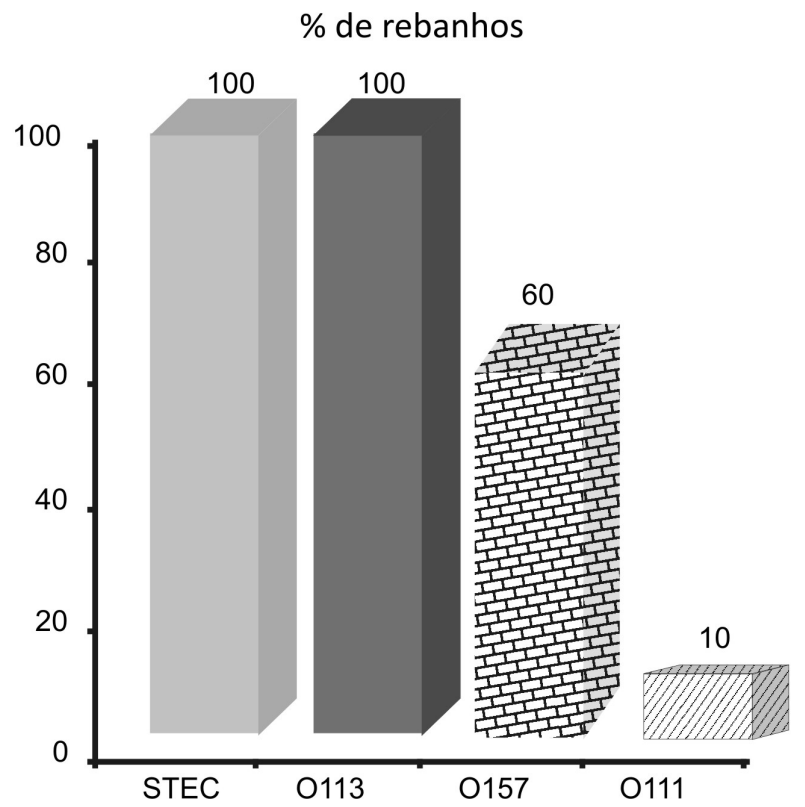

Fig. 3 - Porcentagens de rebanhos, em que Escherichia coli com sequências stx (STEC) e rfb O157, O111 e O113 foram detectadas por Reação em Cadeia de Polimerase em amostras de fezes. Jaboticabal, SP, 2003.

Com exceção do sorogrupo O111, todas as outras STEC foram detectadas com maior frequência em fezes de bovinos sem diarréia. Vários autores sugerem que esses micro-organismos podem fazer parte da microbiota normal de bovinos, uma vez que são isolados com maior frequência de animais saudáveis do que de animais com diarréia (BLANCO et al., 1993). Os animais infectados não são clinicamente identificáveis, o que torna o controle da disseminação entre
Coeficiente de Prevalência

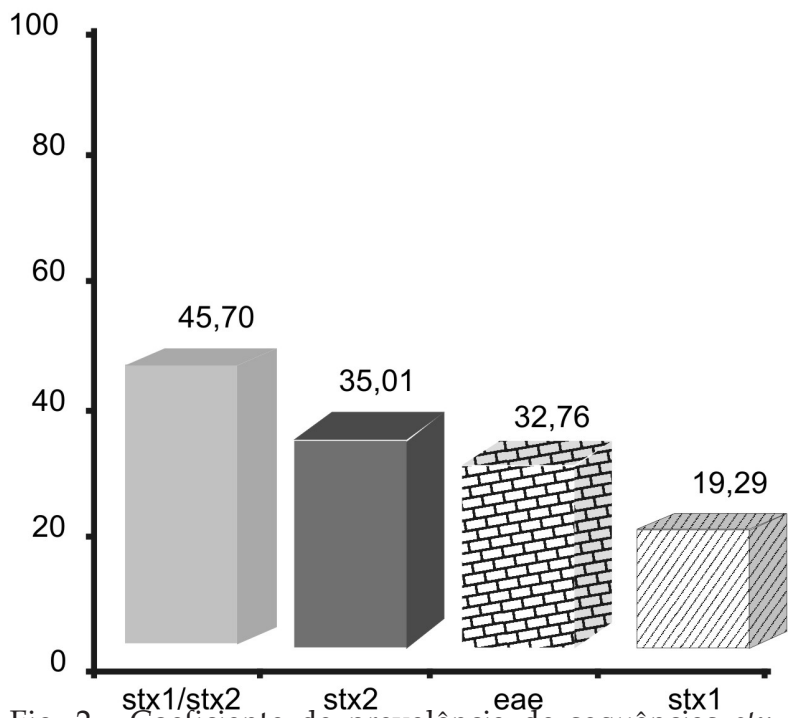

Fig. 2 - Coeficiente de prevalência de sequências stx ${ }^{\prime}$ st $x_{2}$ e $s t x_{1} / s t x_{2}$ de Escherichia coli em amostras de fezes de bovinos STEC positivas e coeficiente de prevalência de sequência eae de Escherichia coli em amostras de fezes de bovinos, detectadas por Reação em Cadeia de Polimerase. Jaboticabal, SP, 2003.

os bovinos difícil (GARBER et al., 1995), facilitando que os portadores contaminem, por meio de suas fezes, o solo, a água, o cocho, equipamentos de ordenha e o ambiente de maneira geral.

Embora, o papel de cada Stx na patogênese das infecções causadas por cepas de EHEC e mais especificamente, no desenvolvimento da SHU, permaneça controverso (RIOS et al., 1999), a maioria dos autores relataquea produçãodeStx2estáassociadaa maior risco de desenvolver SHU (BoERLIN et al., 1999). Além disso, as cepas de STEC que apresentam a sequência eae são mais virulentas para seres humanos (BARRET et al., 1992).

Logo, torna-se relevante o resultado obtido nesta pesquisa, na qual sequências $s t x_{1} / s t x_{2}$, stx e eae apresentaram os maiores coeficientes de prevalência entre as amostras de fezes, respectivamente, $45,70 \%$, 35,01\% e 32,76\% (Fig. 2), o que foi descrito, também, por BlANCO et al. (1997), SANZ et al. (1998), Vold et al. (1998) e CERQUeIrA et al. (1999). Segundo BlanCo et al. (1993) as STEC que produzem Stx ${ }_{2}$ fazem parte do grupo bacteriano que compõe a microbiota intestinal normal do rebanho, talvez por este motivo a sequência st $x$, tenha sido encontrada com bastante frequência. Ademais, as sequências stx ${ }_{1}$ e $s t x_{2}$ estão localizadas em elementos genéticos móveis e podem apresentar diferentes padrões de mobilidade, portanto, talvez ocorra a transferência da sequência stx ${ }_{2}$ de sorotipos não patogênicos para patogênicos com maior frequência (VolD et al., 1998).

As taxas de prevalência de STEC em rebanhos apresentam flutuações significativas ao longo do 
tempo (HANCOCK et al., 1998). Nota-se esta variação quando da comparação entre os resultados obtidos neste estudo (Fig. 3), em que STEC foram identificadas em todos os rebanhos (100\%) e os sorogrupos O157, O111 e O113 foram observados em $60 \%, 10 \%$ e $100 \%$ dos rebanhos, respectivamente, com os resultados obtidos por ViCENTE et al. (2005) que analisando os mesmos rebanhos dois anos antes obtiveram, os seguintes resultados para STEC, O157, O111 e O113, respectivamente, $100 \%, 40 \%, 50 \%$ e $90 \%$.

Testes repetidos demonstraram que STEC estão, pelo menos ocasionalmente, presentes na maioria das fazendas (HANCOCK et al., 1997). Esta afirmação foi confirmada, de acordo com o descrito no parágrafo anterior, em dois testes sucessivos realizados com intervalo de dois anos, uma vez que todos os rebanhos foram positivos para STEC em ambos testes. Tais dados evidenciam que estes grupos de bactérias estão amplamente difundidos entre os animais de propriedades rurais do Município de Jaboticabal, SP.

Considerando a ampla distribuição de STEC em propriedades leiteiras, as altas taxas de prevalência já relatadas e o isolamento de vários sorotipos de alta virulência de rebanhos leiteiros e seus produtos, deveriam ser desenvolvidas estratégias a longo prazo para garantir a segurança de alimentos provenientes desses rebanhos (HusseIn; SAKUMA, 2005).

As fezes dos bovinos são uma fonte potencial para a disseminação de STEC à cadeia de alimentação humana e ao ambiente. Segundo Kudva et al. (1995) a E. coli $\mathrm{O} 157$ pode sobreviver por pelo menos seis semanas nas fezes e possivelmente se multiplicar neste material, além disso, PORTER et al. (1997) relataram que o sorotipo O157:H7 foi isolado com maior frequência de amostras ambientais colhidas próximas ao depósito de esterco dos animais e, rebanhos que pastejam em piquetes tratados com esterco podem apresentar uma prevalência de STEC e O157 maior (HANCOCK et al., 1994). Em um estudo de várias amostras ambientais em propriedades leiterias, STEC foram encontradas em comedouros e baias de bezerros e vacas, demonstrando que o ambiente da propriedade pode permanecer contaminado por meses (BLANCO et al., 2001).

Além dos casos em que a transmissão dá-se diretamente dos animais para os seres humanos, surtos de STEC envolvendo vegetais indicam que as fezes dos bovinos podem contaminar também este tipo de alimento. A contaminação pode ocorrer quando eles são cultivados em campos fertilizados com esterco tratado incorretamente, através da irrigação com água contaminada pelas fezes ou pela água em que são lavados (Solomon et al., 2002).

Embora a incidência de infecção em humanos porSTEC seja, relativamente, baixa, a gravidade dos sintomas e a frequência de sequelas renais e neurológicas são motivos de preocupação. A infecção é de relevância em saúde pública eexiste a necessidade de desenvolver tratamento ou medidas de prevenção. Estratégias para reduzir a prevalência em bovinos são cruciais para a diminuição da incidência de infecção em humanos (STEVENs et al., 2002).

O manejo adequado de dejetos é uma das práticas que evita que as fezes bovinas se tornem fonte de contaminação ambiental por STEC. Existem outras medidas a serem tomadas a fim de reduzir a disseminação das STEC, tais como, evitar a introdução de animais infectados no rebanho, principalmente bezerros enovilhas, fazer a desinfecção adequada das baias antes de introduzir novos animais, controlar o contato entre bezerros e vacas, oferecer água potável, manter bebedouros e comedouros limpos, prover cama adequada e acomodações limpas (RAHN et al., 1997; STEVENS et al., 2002).

Considerando a alta prevalência de STEC em rebanhos leiteiros demonstrada no presente estudo, inclusive a detecção de sorogrupos patogênicos, pode-se concluir que os bovinos leiteiros são importantes reservatórios de STEC, levando, por meio de suas fezes, à contaminação do ambiente rural, o que constitui um risco a saúde pública.

\section{REFERÊNCIAS}

ARTHUR, T.M.; BARKOCY-GALLAGHER, G.A.; RIVERA-BETANCOURT, M.; MOHAMMAD KOOHMARAIE. Prevalence and characterization of non-o157 shiga toxin-producing Escherichia coli on carcasses in commercial beef cattle processing plants. Applied and Environmental Microbiology, v.68, n.10, p.4847-4852, 2002.

BANATVALA, N.A.; GRIFFIN, P.M.; GREENE, K.D.; BARRETT, T.J.; BIBB, W.F.; GREEN, J.H.; WELLS, J.G. The United States national prospective hemolytic uremic syndrome study: microbiologic, serologic, clinical, and epidemiologic findings. Journal of Infectious Diseases, v.183, p.1063-1070, 2001.

BARKOCY-GALLAGHER, G.A.; ARTHUR, T.M.; SIRAGUSA, G.R.; KEEN, J.E.; ELDER, R.O.; LAEGREID, W.W.; KOOHMARAIE, M. Genotypic analyses of Escherichia coli O157:H7 and O157 nonmotile isolates recovered from beef cattle and carcasses at processing plants in the midwestern states of the United States. Applied and Environmental Microbiology, v.67, p.38103818, 2001.

BARRET, T.J.; KAPER, J.B.; JERSE, A.E.; WACHSMUTH, I.K. Virulence factors in Shiga-like toxinproducing Escherichia coli isolated from humans and cattle. Journal of Infectious Diseases, v.165, p.979-980, 1992.

BETTELHEIM, K.A. Non-O157 Verotoxin-producing Escherichia coli: A problem, paradox, and paradigm. 
Non-O157 Vtec Supplement. Society for Experimental Biology and Medicine, v.228, p.333-344, 2003.

BLANCO, M.; BLANCO, J.; BLANCO, J.E.; RAMOS, J. Enterotoxigenic, verotoxigenic, and necrotoxigenic Escherichia coli isolated from cattle in Spain. American Journal of Veterinary Research, v.54, p.1446-1451, 1993.

BLANCO, M.; BLANCO, J.E.; BLANCO, J. MORA, A.; PRADO, C.; ALONSO, M.P.; MOURIÑO, M.; MADRID, C.; BALSALOBRE, C.; JUÁREZ, A. Distribution and characterization of faecal verotoxin producing Escherichia coli (VTEC) isolated from health cattle. Veterinary Microbiology, v.54, p.309-319, 1997.

BLANCO, J.; BLANCO, M.; BLANCO, J.E.; MORA, A.; ALONSO, M.P.; GONZALEZ, E.A.; BERNARDEZ, M.I. Epidemiology of verocytotoxigenic Escherichia coli (VTEC) in ruminants. In: DUFFY, G., GARVEY, P., McDOWELL, D. (Ed.). Verocytotoxigenic Escherichia coli. Trumbull: Food and Nutrition Press, 2001. p.113-148.

BOERLIN, P.; MCEWEN, S.A.; BOERLIN-PETZOLD, F.; WILSON, J.B.; JOHNSON, R.P.; GYLES, C.L.

Associations between virulence factors of Shiga toxin-producing Escherichia coli and disease in humans. Journal of Clinical Microbiology, v.37, p.497-503, 1999.

BUSATO, A.; HOFER, D.; LENTZE, T.; GAILLARD, C.; BURNENS, A. Prevalence and infection risks of zoonotic enteropathogenic bacteria in Swiss cow-calf farms. Veterinary Microbiology, v.69, p.251-263, 1999.

CERQUEIRA, A.M.F.; TIBANA, A.; GUTH, B.E.C. High occurrence of Shiga-like toxin-producing Escherichia coli isolated from raw beef products in Rio de Janeiro City, Brazil. Journal of Food Protection, v.60, n.2, p.177-180, 1997.

CERQUEIRA, A.M.F.; GUTH, B.E.C.; JOAQUIM, R.M.; ANDRADE, J.R.C. High occurrence of Shiga toxinproducing Escherichia coli (STEC) in healthy cattle in Rio de Janeiro State, Brazil. Veterinary Microbiology, v.70, p.111-121, 1999.

CHAPMAN, P.A.; WRIGHT, D.J.; HIGGINS, R. Untreated milk as a source of verotoxigenic $E$ coli $\mathrm{O} 157$. Veterinary Record, v.133, p.171-172, 1993.

CHINA, B.; PIRSON, V.; MAINIL, J. Typing of bovine attaching and effacing Escherichia coli by multiplex in vitro amplification of virulence-associated genes. Applied and Environmental Microbiology, v.62, n.9, p.34623465, 1996.

DOYLE, M.P.; ZHAO, T.; MENG, J.; ZHAO, S., Escherichia coli O157:H7. In: DOYLE, M. P.; BEUCHAT, L.R.; MONTVILLE, T.J. (Ed.). Food microbiology: fundamentals and frontiers. ASM Press, 1995. p.171-191.

GARBER, L.P.; WELLS, J.; HANCOCK, D.D.; DPYLE, M.P.; TUTTLE, J.; SHERE, J.A.; ZHAO, T. Risk factors for fecal shedding of Escherichia coli O157:H7 in dairy calves. Journal of the American Veterinary Medical Association, v.207, n.1, p.46-49, 1995.

GRIFFIN, P.M.; TAUXE, R.V. The epidemiology of infections caused by Escherichia coli O157:H7, other enterohemorrhagic E. coli, and the associated hemolytic uremic syndrome. Epidemiological Review, v.13, p.60-98, 1991.

GYLES, C.; JOHNSON, R.; GAO, A.; ZIEBELL, K.; PIERARD, D.; ALEKSIC, S.; BOERLIN, P. Association of enterohemorrhagic Escherichia coli hemolysin with serotypes of Shiga-like-toxin-producing Escherichia coli of human and bovine origins. Applied and Environmental Microbiology, v.64, p.4134-4141, 1998.

HANCOCK, D.D. BESSER, T.E.; KINSEL, M.L.; TARR, P.I.; RICE, D.H.; PAROS, M.G. The prevalence of Escherichia coli O157:H7 in dairy and beef cattle in Washington State. Epidemiology and Infection, v.113, p.199-207, 1994.

HANCOCK, D.D.; BESSER, T.E.; RICE, D.H.; HERRIOTT, D.E.; TARR, P.I. A longitudinal study of Escherichia coli O157 in fourteen cattle herds. Epidemiology and Infection, v.118, p.193-195, 1997.

HANCOCK, D.D.; BESSER, T.E.; RICE, D.H.; EBEL, E.D.; HERRIOTT, D.E.; CARPENTER, L.V. Multiple sources of Escherichia coli O157 in feedlots and dairy farms in the Northwestern USA. Preventive Veterinary Medicine, v.35, p.11-19, 1998.

HUSSEIN ,H.S.; SAKUMA, T. Invited Review: Prevalence of shiga toxin-producing Escherichia coli in dairy cattle and their products. Journal of Dairy Science, v.88, p.450-465, 2005.

KARMALI, M.A.; PETRIC, M.; LIM, C.; HEMING, P.C.; ARBUS, G.S.; LIOR, H. The association between hemolytic uremic syndrome and infection by Verotoxinproducing Escherichia coli. Journal of Infectious Diseases, v.151, p.775-782, 1985.

KOBAYASHI, H.; SHIMADA, J.; NAKAZAWA, M.; MOROZUMI, T.; POHJANVIRTA, T.; PELKONEN, S.; YAMAMOTO, K. Prevalence and characteristics of Shiga toxin-producing Escherichia coli from healthy cattle in Japan. Applied and Environmental Microbiology, v.67, p.484-489, 2001.

KUDVA, I.T.; HATFIELD, P.G.; HOVDE, C.J. Effect of diet on the shedding of Escherichia coli O157:H7 in a sheep model. Applied and Environmental Microbiology, v.61, n.4, p.1363-1370, 1995.

MOREIRA, C.N.; PEREIRA, M.A.; BROD, C.S.; RODRIGUES, D.P.; CARVALHAL, J.B.; ALEIXO, J.A.G. Shiga toxin-producing Escherichia coli (STEC) isolated from healthy dairy cattle in southern Brazil. Veterinary Microbiology, v.93, p.179-183, 2003. 
ORDEN, J.A.; CID, D.; RUIZ-SANTA-QUITERIA, J.A.; GARCÍA, S.; MARTINEZ, S.; DE LA FUENTE, R. Verotoxin-producing Escherichia coli (VTEC), enteropathogenic E. coli (EPEC) and necrotoxigenic $E$. coli (NTEC) isolated from healthy cattle in Spain. Journal of Applied Microbiology, v.93, p.29-35, 2002.

PATON, J.C.; PATON, A.W. Pathogenesis and diagnosis of shiga toxin-producing Escherichia coli infections. Clinical Microbiology Reviews, v.11, n.3, p.450-479, 1998.

PATON, A.W.; PATON, J.C. Direct detection of shiga toxigenic Escherichia coli strains belonging to serogroups O111, O157, and O113 by multiples PCR. Journal of Clinical Microbiology, v.37, n.10, p.3362-3365, 1999.

PATON, A.W.; PATON, J.C. Multiples PCR for direct detection of shiga toxigenic Escherichia coli strains producing the novel subtilase cytotoxin. Journal of Clinical Microbiology, v.43, n.6, p.2944-2947, 2005.

PORTER, J.; MOBBS, K.; HART, C.A.; SAUNDERS, J.R.; PICKUP, J.R.; EDWARDS, C. Detection, distribution and probable fate of Escherichia coli $\mathrm{O} 157$ from asyntomatic cattle on a dairy farm. Journal of Applied Microbiology, v.83, p.297-306, 1997.

RAHN, K.; RENWICK, S.A.; JOHSON, R.P.; WILSON, J.B.; CLARK, R.C.; ALVES, D.; McEWEN, S.; LIOR, H.; SPIKA, J. Persistence of Escherichia coli O157:H7 in dairy cattle and the dairy farm environment. Epidemiology and Infection, v.119, p.251-259, 1997.

RIOS, M.; PRADO, V.; TRUCKSIS, M.; ARELLANO, C.; BORIE, C.; ALEXANDRE, M; FICA, A.; LEVINE, M.M. Clonal diversity of enterohemorrhagic Escherichia coli from patients with hemolytic-uremic syndrome, asymptomatic subjects, animal reservoirs, and food products. Journal of Clinical Microbiology, v.37, n.3, p.778-781, 1999.

SAMBROOK, J., FRITSCH, E.F., MANIATIS, T. Molecular cloning: a laboratory manual. New York: Cold Spring Harbor Press, 1989. p.9.16-9.19.
SANZ, M.E.; VINAS, M.R.; PARMA, A.E. Prevalence of bovine verotoxin-producing Escherichia coli in Argentina. European Journal of Epidemiology, v.14, p.399-403, 1998.

SOLOMON, E.B.; YARON, S.; MATTHEWS, K.R. Transmission of Escherichia coli O157:H7 from contaminated manure and irrigation water to lettuce plant tissue and its subsequent internalization. Applied and Environmental Microbiology, Washington, v.68,p. 397-400, 2002.

STEVENS, M.P.; Van DIEMEN, P.M.; DZIVA, F.; JONES, P.W.; WALLIS, T.S. Options for the control of enterohaemorrhagic Escherichia coli in ruminants. Microbiology, v.148, p.3767-3778, 2002.

VICENTE, H.I.G.; AMARAL, L.A.; CERQUEIRA, A.M.F. Shigatoxigenic Escherichia coli serogroups o157, o111 and o113 in feces, water and milk samples from dairy farms. Brazilian Journal of Microbiology, v.36, n.3, p.217-222, 2005.

VOLD, L.; JOHANSEN, B.K.; KRUSE, H.; SKJERVE, E.; WASTESON, Y. Occurrence of shigatoxinogenic Escherichia coli $\mathrm{O} 157$ in Norwegian cattle herds. Epidemiology and Infection, v.120, p.21-28, 1998.

WELLS, J.G.; SHIPMAN, L.D.; GREENE, K.D.; SOWERS, E.G.; GREEN, J.H.; CAMERON, D.N.; DOWNES, F.P.; MARTIN, M.L.; GRIFFIN, P.M.; OSTROFF, S.M.; POTTER, M.E.; TAUXE, R.V.; WACHSMUTH, I.K. Isolation of Escherichia coli serotype O157:H7 and other Shiga-like-toxin-producing E. coli from dairy cattle. Journal of Clinical Microbiology, v.29, p.985-989, 1991.

WHO SCIENTIFIC WORKING GROUP MEETING. 1998, Berlin, Germany 23-26 June. WHO/CSR/ APH/98.8. Zoonotic non-O157 shiga toxin-producing Escherichia coli (STEC). Report of a World Health Organization Department of Communicable Disease Surveillance and Response. http:/ / www.who.int/emc

Recebido em 5/5/09

Aceito em 16/11/10 